\title{
Cardiac and skeletal muscle abnormality in taurine transporter-knockout mice
}

\author{
Takashi Ito ${ }^{1}$, Shohei Oishi ${ }^{2}$, Mika Takai ${ }^{2}$, Yasushi Kimura², Yoriko Uozumi ${ }^{2}$, Yasushi Fujio ${ }^{2}$, Stephen W Schaffer ${ }^{3}$, \\ Junichi Azuma ${ }^{1 *}$
}

From $17^{\text {th }}$ International Meeting of Taurine

Fort Lauderdale, FL, USA. 14-19 December 2009

\begin{abstract}
Taurine, a sulfur-containing $\beta$-amino acid, is highly contained in heart and skeletal muscle. Taurine has a variety of biological actions, such as ion movement, calcium handling and cytoprotection in the cardiac and skeletal muscles. Meanwhile, taurine deficiency leads various pathologies, including dilated cardiomyopathy, in cat and fox. However, the essential role of taurine depletion on pathogenesis has not been fully clarified. To address the physiological role of taurine in mammalian tissues, taurine transporter-(TauT-) knockout models were recently generated. TauTKO mice exhibited loss of body weight, abnormal cardiac function and the reduced exercise capacity with tissue taurine depletion. In this chapter, we summarize pathological profile and histological feature of heart and skeletal muscle in TauTKO mice.
\end{abstract}

\section{Background}

Taurine is a most abundant free amino acid in mammalian tissues with an intracellular concentration of 5-20 $\mu \mathrm{mol} / \mathrm{g}$ wet weight $[1,2]$. A number of evidences revealed that taurine is a cytoprotective agent. Supplementation of taurine is effective to a variety of disorders, such as cardiovascular diseases, skeletal muscle disorders, etc. Meanwhile, taurine deficiency related to some kinds of pathophysiological conditions in cats and foxes, such as dilated cardiomyopathy, retinal degradation and reproduction[3-5].

Taurine transporter (TauT; SLC6a6) is a sodium and chloride ion-dependent transporter, and is expressed ubiquitously in mammalian tissues [6]. Since the capacity to synthesize taurine in most tissues, such as heart and skeletal muscle, is limited, maintenance of the large intracellular taurine pool may depend upon uptake of the amino acid from extracellular space via TauT. This transport process requires the accumulation of taurine against a substantial concentration gradient, as the

\footnotetext{
* Correspondence: azuma@huhs.ac.jp

'Department of Pharmacy, School of Pharmacy, Hyogo University of Health Sciences, Kobe, Japan

Full list of author information is available at the end of the article
}

concentration of taurine is 100 fold less in the plasma $(20-100 \mu \mathrm{M})$ than in the tissues.

Recently, transgenic mice lacking TauT gene have been generated by two groups $[7,8]$. A variety of disorders has been reported in various tissues, such as eye, kidney, heart, muscle, etc., accompanied with drastic taurine deficiency in TauTKO mice [7-10]. In this chapter, we report the phenotype of TauTKO mice and discuss the role of taurine deficiency in hearts and skeletal muscles.

\section{Analysis of taurine transporter knockout mice}

In our TauTKO mice, targeting construct for generation of transgenic mice was designed to replace exons 2-4 of the TauT gene with a cassette containing neomycinresistance gene [7]. While a truncated TauT mRNA lacking exon 2-4 was detected in TauTKO tissues, taurine influx was eliminated in the cells isolated from TauTKO mice, indicating loss of taurine transport activity in TauTKO mice. Tissue taurine level is severely decreased in several tissues. Especially, cardiac taurine could not be detected in TauTKO mice, and skeletal muscle taurine level is decreased by $96 \%$ in TauTKO mice compared with wild-type mice. Similarly, in another TauTKO mouse model which was reported by 
Heller-Stilb et al, is lacking exon 2 of TauT gene, and taurine level in skeletal and cardiac muscles was decreased by about $98 \%$, while taurine level in brain, kidney and liver is decreased by 70-90 \% compared to wild-type mice [8]. These data illustrate that maintenance of intracellular taurine pool in cardiac and skeletal muscle is extremely dependent upon taurine transport activity.

TauTKO mice exhibited a lower body weight than their control littermates. Furthermore, knocking out TauT causes a decrease in tissue weight, such as heart, skeletal muscle, brain etc $[7,8]$. Food and water intake were identical in the TauTKO and control mice.

\section{Cardiac Phenotype of TauTKO mice}

Oral supplementation of taurine is effective to animals and human patients with congestive heart failure and cardiomyopathy $[11,12]$, indicating that taurine would play an important role in cardiac homeostasis and cardioprotection against pathological stress. It has been reported that taurine-deficient diet impaired cardiac function and led to dilated cardiomyopathy in cat and fox, which have very low capacity of taurine synthesis $[3,13]$. Furthermore, drug-induced taurine deficiency by the inhibition of taurine uptake using guanidinoethane sulfonate (GES) or $\beta$-alanine led to some cardiac defects in mice or rats $[11,14]$.

In TauTKO model, we determined the cardiac function of TauTKO mice. Echocardiographic analysis revealed that fractional shortening was diminished in the old (>9-month-old) TauTKO mice, whereas we failed to detect a functional difference between the young (5-month-old) wild-type mice and $\mathrm{KO}$ mice (Table 1) [7]. Detailed functional analysis on Langendorff perfused heart also demonstrated the age-dependent cardiac dysfunction in TauTKO mice (Unpublished data).

It is well established that the expression of fetal genes, including atrial natriuretic peptide (ANP), brain natriuretic peptide (BNP) and $\beta$-myosin heavy chain $(\beta \mathrm{MHC})$, is reactivated in a variety of cardiac pathological conditions, such as ischemia, heart failure, hypertrophy and atrophy [15]. These cardiac failure markers were significantly elevated in both young and old

Table 1 Echocardiographic analysis of young and old TauTKO mice

\begin{tabular}{lcccc}
\hline & \multicolumn{2}{c}{ Young (5-month-old) } & \multicolumn{2}{c}{ Old (>9-month-old) } \\
\hline Genotype & WT $(\mathrm{n}=3)$ & TauTKO $(\mathrm{n}=4)$ & $W T(\mathrm{n}=5)$ & TauTKO $(\mathrm{n}=7)$ \\
LVIDd $(\mathrm{cm})$ & $0.37 \pm 0.03$ & $0.35 \pm 0.03$ & $0.41 \pm 0.01$ & $0.40 \pm 0.01$ \\
LVIDs (cm) & $0.25 \pm 0.04$ & $0.26 \pm 0.02$ & $0.27 \pm 0.01$ & $0.31 \pm 0.01$ \\
FS (\%) & $30.87 \pm 9.22$ & $25.65 \pm 4.75$ & $34.18 \pm 2.52$ & $22.48 \pm 1.92^{*}$ \\
\hline
\end{tabular}

LVIDd; left ventricular end-diastolic internal dimension, LVIDs; left ventricular end-systolic internal dimension, FS; fractional shortening, ${ }^{*} ; \mathrm{p}<0.01$ v.s. WT.
TauTKO mice (Fig. 1) [7]. Consistent with the cardiac function, the inductions of these genes were more significant in the old TauTKO mice. These data indicate that knockout of the TauT gene leads to an age-dependent dilated cardiomyopathy.

On the other hand, Warskulat et al. reported that TauTKO mice exhibited normal cardiac function [9]. These inconsistent results between two TauTKO models may be due to the difference of genetic background, since the difference of inbred strains affects the cardiovascular phenotypes and susceptibilities against pathological stressors in mice [16]. We used mice which backcrossed at least 4 times into $\mathrm{C} 57 \mathrm{BL} / 6$ line to minimize genetic differences, while Warskulat et al. reported the use of F2 mixed C57BL/6 amd 129/SvJ strains. Meanwhile, Warskulat et al. also reported that biomarker genes for heart failure, including ANP, BNP and CARP, are upregulated in TauTKO hearts consistent with our TauTKO model [17]. Furthermore, they also demonstrated that the TauTKO hearts showed a switch from alpha-actin 1 (skeletal muscle type) to alpha-actin 2 (smooth muscle type) expression [17]. These data suggest that other TauTKO mice (Warskulat et al) may have the aptitude toward heart failure, and hearts may be more susceptible to exogenous stresses in TauTKO mice.

Histological analysis revealed that TauTKO mice undergo ventricular remodeling, characterized by dilated ventricles and reductions in ventricular wall thickness [7]. Furthermore, cross sectional area of ventricular cardiomyocytes was decreased in TauTKO hearts, implying the importance of taurine for cell size. Surprisingly, cardiac fibrosis was not observed in TauTKO heart. Transition electron microscopic analysis demonstrated that TauTKO hearts exhibited significant ultrastructural damage of myofilament and mitochondria. Furthermore, another important feature of TauTKO mice is the presence of autophagosome containing mitochondria. Autophagy is a biological process, in which cells degrade and recycle intracellular macromolecules and organelles. It is considered to represent a cellular adaptation to ensure survival, as injured and potentially damaging organelles are targeted for elimination. There are several triggers of mitochondrial autophagy, such as mtDNA damage, lipid peroxidation and the mitochondrial permeability transition [18-20]. Thus, the triggers themselves might provide useful information on the pathology that is occurring in the taurine knockout heart.

\section{Phenotype of exercise capacity and skeletal muscle}

Taurine is well known to modulate ion movement and play a role in the excitation-contraction coupling 


\section{age 3-month-old 1-year-old genotype wt KO wt KO wt KO wt KO $\beta$-MHC
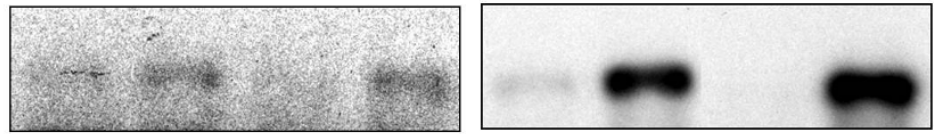 \\ BNP
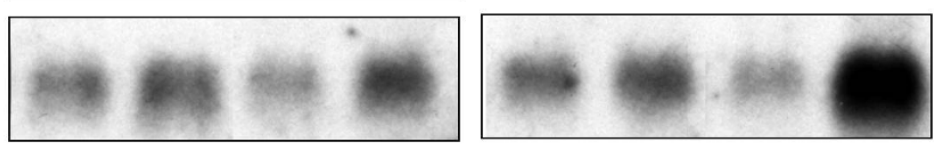 \\ GAPDH
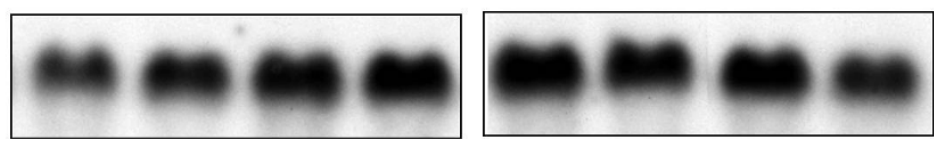

Figure 1 Age-dependent induction of heart failure markers in TauTKO mice Northern blot analyses of mRNA from wild-type (WT) and TauTKO (KO) hearts revealed the increased expression of mRNA for brain natriuretic peptide (BNP) and $\beta$-myosin heavy chain ( $\beta M H C)$ in TauTKO mice. GAPDH mRNA was measured to internal control.

mechanism in skeletal muscle [21], 22. It has been reported that supplementation of taurine improved exercise capacity in rats and attenuated the exercise-induced oxidative injury [23,24]. However, the effect of taurine deficiency on the exercise has been unclear. It has been reported that supplementation of GES to decrease in taurine content in muscles reduced force output and increased the endurance of skeletal muscles in rats [25]. However, since GES itself directly increases susceptibility to $\mathrm{Ca}^{2+}$ on isolated muscle skinned fiber, the pharmacological action of GES must influence to the experiments using taurine depleted animal models [26].

In TauTKO mice, weight-loaded swimming test revealed that exercise endurance time was severely reduced compared to wild-type mice $(118 \pm 2.3 \mathrm{~min}$ in wild-type vs $10 \pm 2.5 \mathrm{~min}$ in TauTKO, $\mathrm{p}<0.01$ ) [7]. Additionally, forced treadmill test on uphill road also revealed that the duration of running time to exhaustion is reduced in TauTKO mice $(49.0 \pm 11.0 \mathrm{~min}$ in wild-type vs $14.8 \pm 9.2 \mathrm{~min}$ in TauTKO, $\mathrm{p}<0.01)$. Warskulat et al. have also reported that total running distance to exhaustion on the treadmill is reduced by more than $80 \%$ in TauTKO mice [9]. These data indicate that taurine deficiency may reduce muscle function in skeletal muscles. Moreover, Warskulat et al. demonstrated that X-ray studies of the skeleton did not reveal morphological disorders in TauTKO mice, indicating that skeletal muscle abnormalities may be associated with the reduction of exercise capacity in TauTKO mice.

Since TauTKO mice lost muscle mass, the skeletal muscle was analyzed histologically [7]. As expected for atrophic muscle, the myofibrillar cross sectional area of the tibial anterior muscle of the mutant mice was remarkably reduced compared to that of their littermate
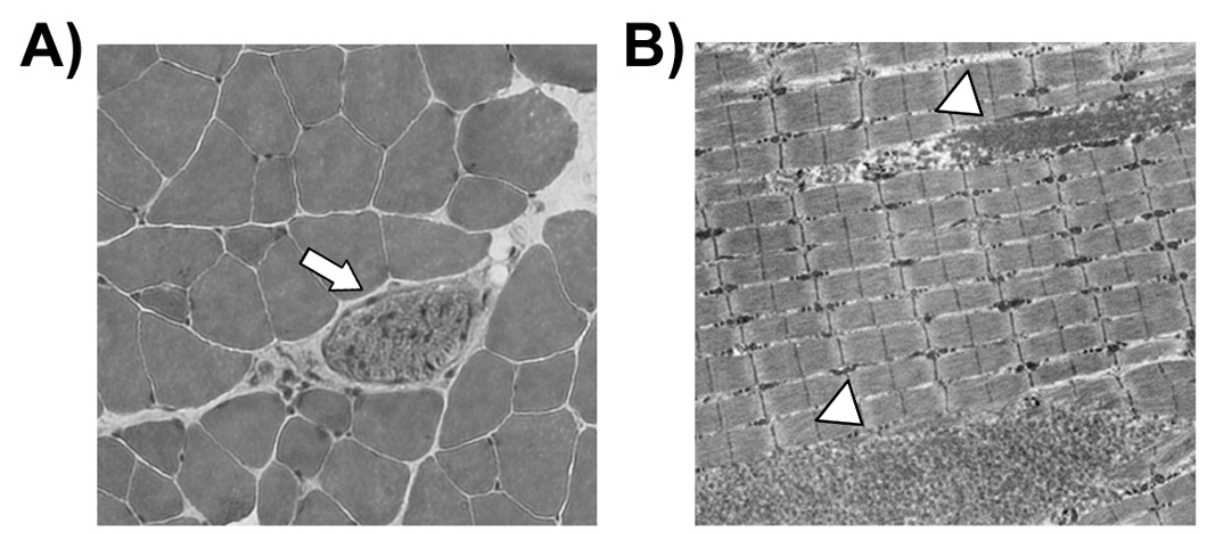

Figure 2 Histological disorders in skeletal muscle of TauTKO mice. A) Representative micrographs of tibial anterior muscle sections of TauTKO mice. The arrow indicates a necrotic cell. B) Representative electron micrographs of tibial anterior muscle sections of TauTKO mice. Magnification; $\times 3000$. The arrowheads indicate myofilament fragmentations. 
controls. Furthermore, necrotic cells were detected in TauTKO muscles (Fig. 2A), indicating that taurine may play a role in the regulation of cell volume and cell survival in skeletal muscle cells. Electron microscopy revealed some kinds of ultrastructural abnormalities in TauTKO muscle, such as filament fragmentation, membranous cytoplasmic body and lipid droplet (Fig. 2B). These observations suggest that taurine depletion may result in destabilization of myofilament and other cytosolic organelle in skeletal muscle. Clearly, further studies are required to clarify the mechanism underlying taurine depletion-induced muscle disorders.

\section{Conclusion}

TauTKO mice displayed the dilated cardiomyopathy, consistent with the phenotype of taurine-depleted cats. These data illustrate that taurine depletion is an independent etiology of cardiomyopathy. This model will provide benefits to find the molecular mechanism underlying taurine-depleted cardiomyopathy. Furthermore, lacking TauT results in aging-dependent cardiac dysfunction, indicating that taurine deficient hearts might be less able to tolerate aging. Aging-dependent disorders have been reported in several tissues of TauTKO mice, including visual, auditory, olfactory and renal dysfunctions and hepatitis $[10,27,28]$. Taurine deficiency i likely to increase susceptibility against stress, such as oxidative stress, which in turn causes to accelerated aging.

\section{Acknowledgements}

This study was supported in part by a Grants-in-Aid from the Ministry of Health, Labor and Welfare and from the Ministry of Education, Science, Sports and Culture of Japan. This study was also partly granted by Taisho Pharmaceutical Ltd.

This article has been published as part as part of Journal of Biomedical Science Volume 17 Supplement 1, 2010: Proceedings of the 17th International Meeting of Taurine. The full contents of the supplement are available online at http://www.jbiomedsci.com/supplements/17/S1.

\section{Author details}

${ }^{1}$ Department of Pharmacy, School of Pharmacy, Hyogo University of Health Sciences, Kobe, Japan. ${ }^{2}$ Department of Clinical Pharmacology and Pharmacogenomics, Graduate School of Pharmaceutical Sciences, Osaka University, Osaka, Japan. ${ }^{3}$ Department of Pharmacology, College of Medicine, University of South Alabama, Mobile, AL, USA.

\section{Competing interests}

The authors declare that they have no competing interests.

Published: 24 August 2010

\section{References}

1. Chapman RA, Suleiman MS, Earm YE: Taurine and the heart. Cardiovasc Res 1993, 27:358-63.

2. Chesney RW: Taurine: its biological role and clinical implications. Adv Pediatr 1985, 32:1-42

3. Pion PD, Kittleson MD, Rogers QR, Morris JG: Myocardial failure in cats associated with low plasma taurine: a reversible cardiomyopathy. Science $1987,237: 764-8$
4. Hayes KC, Carey RE, Schmidt SY: Retinal degeneration associated with taurine deficiency in the cat. Science 1975, 188:949-51.

5. Sturman JA: Dietary taurine and feline reproduction and development. J Nutr 1991, 121:S166-70.

6. Uchida S, Kwon HM, Yamauchi A, Preston AS, Marumo F, Handler JS: Molecular cloning of the cDNA for an MDCK cell $\mathrm{Na}(+)-$ and $\mathrm{Cl}$ (-)-dependent taurine transporter that is regulated by hypertonicity. Proc Natl Acad Sci U S A 1992, 89:8230-4.

7. Ito T, Kimura Y, Uozumi Y, Takai M, Muraoka S, Matsuda T, Ueki K, Yoshiyama M, Ikawa M, Okabe M, et al: Taurine depletion caused by knocking out the taurine transporter gene leads to cardiomyopathy with cardiac atrophy. J Mol Cell Cardiol 2008, 44:927-37.

8. Heller-Stilb B, van Roeyen C, Rascher K, Hartwig HG, Huth A, Seeliger MW, Warskulat $U$, Haussinger D: Disruption of the taurine transporter gene (taut) leads to retinal degeneration in mice. Faseb J 2002, 16:231-3.

9. Warskulat U, Flogel U, Jacoby C, Hartwig HG, Thewissen M, Merx MW, Molojavyi A, Heller-Stilb B, Schrader J, Haussinger D: Taurine transporter knockout depletes muscle taurine levels and results in severe skeletal muscle impairment but leaves cardiac function uncompromised. Faseb J 2004, 18:577-9.

10. Warskulat U, Heller-Stilb B, Oermann E, Zilles K, Haas H, Lang F, Haussinger D: Phenotype of the taurine transporter knockout mouse. Methods Enzymol 2007, 428:439-58.

11. Takihara K, Azuma J, Awata N, Ohta H, Hamaguchi T, Sawamura A, Tanaka Y, Kishimoto S, Sperelakis N: Beneficial effect of taurine in rabbits with chronic congestive heart failure. Am Heart J 1986, 112:1278-84.

12. Azuma J, Hasegawa H, Sawamura A, Awata N, Ogura K, Harada H, Yamamura Y, Kishimoto S: Therapy of congestive heart failure with orally administered taurine. Clin Ther 1983, 5:398-408.

13. Moise NS, Pacioretty LM, Kallfelz FA, Stipanuk MH, King JM, Gilmour RF Jr.: Dietary taurine deficiency and dilated cardiomyopathy in the fox. Am Heart J 1991, 121:541-7.

14. Lake N: Loss of cardiac myofibrils: mechanism of contractile deficits induced by taurine deficiency. Am J Physiol 1993, 264:H1323-6.

15. Rajabi M, Kassiotis C, Razeghi P, Taegtmeyer H: Return to the fetal gene program protects the stressed heart: a strong hypothesis. Heart Fail Rev 2007, 12:331-43.

16. Barrick CJ, Rojas M, Schoonhoven R, Smyth SS, Threadgill DW: Cardiac response to pressure overload in 129S1/SvImJ and C57BL/6J mice: temporal- and background-dependent development of concentric left ventricular hypertrophy. Am J Physiol Heart Circ Physiol 2007, 292:H2119-30.

17. Warskulat U, Andree B, Lusebrink J, Kohrer K, Haussinger D: Switch from actin alpha1 to alpha2 expression and upregulation of biomarkers for pressure overload and cardiac hypertrophy in taurine-deficient mouse heart. Biol Chem 2006, 387:1449-54.

18. Scherz-Shouval R, Elazar Z: ROS, mitochondria and the regulation of autophagy. Trends Cell Biol 2007, 17:422-7.

19. Rodriguez-Enriquez S, He L, Lemasters JJ: Role of mitochondrial permeability transition pores in mitochondrial autophagy. Int J Biochem Cell Biol 2004, 36:2463-72.

20. Dirks AJ, Hofer T, Marzetti E, Pahor M, Leeuwenburgh C: Mitochondrial DNA mutations, energy metabolism and apoptosis in aging muscle. Ageing Res Rev 2006, 5(z):179-95.

21. Conte Camerino D, Tricarico D, Pierno S, Desaphy JF, Liantonio A, Pusch M, Burdi R, Camerino C, Fraysse B, De Luca A: Taurine and skeletal muscle disorders. Neurochem Res 2004, 29:135-42.

22. De Luca A, Pierno S, Tricarico D, Desaphy JF, Liantonio A, Barbieri M, Camerino C, Montanari L, Camerino DC: Taurine and skeletal muscle ion channels. Adv Exp Med Biol 2000, 483:45-56.

23. Yatabe $\mathrm{Y}$, Miyakawa S, Ohmori H, Mishima H, Adachi T: Effects of taurine administration on exercise. Adv Exp Med Biol 2009, 643:245-52.

24. Dawson R Jr., Biasetti M, Messina S, Dominy J: The cytoprotective role of taurine in exercise-induced muscle injury. Amino Acids 2002, 22:309-24.

25. Hamilton EJ, Berg HM, Easton CJ, Bakker AJ: The effect of taurine depletion on the contractile properties and fatigue in fast-twitch skeletal muscle of the mouse. Amino Acids 2006, 31:273-8.

26. Cuisinier C, Gailly P, Francaux M, Lebacq J: Effects of guandinoethane sulfonate on contraction of skeletal muscle. Adv Exp Med Biol 2000, 483:403-9.

27. Huang DY, Boini KM, Lang PA, Grahammer F, Duszenko M, Heller-Stilb B, Warskulat U, Haussinger D, Lang F, Vallon V: Impaired ability to increase 
water excretion in mice lacking the taurine transporter gene TAUT.

Pflugers Arch 2006, 451:668-77.

28. Warskulat U, Borsch E, Reinehr R, Heller-Stilb B, Monnighoff I, Buchczyk D,

Donner M, Flogel U, Kappert G, Soboll S, et al: Chronic liver disease is

triggered by taurine transporter knockout in the mouse. Faseb J 2006,

$$
\text { 20:574-6. }
$$

doi:10.1186/1423-0127-17-S1-S20

Cite this article as: Ito et al:: Cardiac and skeletal muscle abnormality in taurine transporter-knockout mice. Journal of Biomedical Science 201017

(Suppl 1):S20.

Submit your next manuscript to BioMed Central and take full advantage of:

- Convenient online submission

- Thorough peer review

- No space constraints or color figure charges

- Immediate publication on acceptance

- Inclusion in PubMed, CAS, Scopus and Google Scholar

- Research which is freely available for redistribution

Submit your manuscript at www.biomedcentral.com/submit
C Biomed Central 